\title{
Aeroelastic Tailoring for Maximizing Sailplane Average Cross-Country Speed
}

\author{
Christopher A. Lupp * and Carlos E. S. Cesnik ${ }^{\dagger}$ \\ University of Michigan, Ann Arbor, MI 48109
}

\begin{abstract}
This paper describes the development of an aeroelastic simulation tool designed to aid the optimization process for anisotropic wings in low subsonic flow and subsequent aeroelastic tailoring of a sailplane wing to maximize its cross-country speed. To this end a nonlinear, quasi-three dimensional structural beam solver is coupled with a three dimensional panel code. The code is then verified using a published, theoretical configuration. Simulation results closely correspond to the reference values and show very fast convergence. Using the cross-section flexibility matrices as design variables, the deflections of a conceptual sailplane wing are optimized for multiple operating points according to crosscountry theory. The final configuration features a significant improvement in cross country speed compared to the rigid wing and an incremental improvement when compared to the flexible base configuration.
\end{abstract}

\section{Nomenclature}

$v \quad$ horizontal speed

$w \quad$ vertical speed

$w_{c} \quad$ vertical climb-rate

$\gamma \quad$ glide angle

$d w$ thermal upwind gradient

$v_{\text {avg }}$ average cross country speed

$t_{c} \quad$ climb time

$t_{g} \quad$ glide time

$\rho$ density

$c_{L} \quad$ lift coefficient

$c_{D} \quad$ drag coefficient

$S$ projected wing surface area

$L \quad$ lift force

$D$ drag force

$F_{C F}$ centrifugal force

\author{
$m$ mass \\ $g$ gravitational acceleration \\ $\phi \quad$ bank angle \\ $K^{-1}$ cross-section flexibility matrix \\ $E \quad$ Young's modulus \\ $G \quad$ shear modulus \\ $\nu \quad$ Poisson's ratio \\ $\varphi \quad$ fiber volume content \\ Subscripts \\ $\| \quad$ property in fiber direction \\ $\perp \quad$ property perpendicular to the fiber direction \\ $f \quad$ property of the fiber \\ $m$ property of the matrix
}

\section{Introduction}

Sailplanes have been technology testbeds since the beginnings of aviation. As aviation technology evolved, so did the complexity and capabilities of high performance gliders, moving from wood to some of the first composite wings and providing $L / D$ values in excess of 50 . Modern sailplanes feature very slender wings and share many characteristics of High Altitude Long Endurance (HALE) aircraft, which play a valuable role varying from surveillance capabilities to atmospheric research. Both aircraft types achieve their high performance through high aspect ratio wings that are carefully tailored aerodynamically. The deflections encountered by these light, high aspect ratio wings may therefore alter the wing's aerodynamics and prove detrimental to aircraft performance. This is particularly true if the aircraft regularly operates at multiple

*Graduate Student Research Assistant, Department of Aerospace Engineering, AIAA Member, clupp@umich.edu

${ }^{\dagger}$ Professor, Department of Aerospace Engineering, AIAA Fellow, cesnik@umich.edu 
operating points. Aeroelastic tailoring, however, offers designers not only the possibility to correct unwanted deformations and potentially lower structural weight, but also could be used to adapt an aircraft's performance to multiple operating points.

The concept of aeroelastic tailoring can be traced back to 1949, when Max Munk filed a patent for a propeller that elastically adjusts its twist for different thrust levels [1,2. However, it was not until 1986 that a working definition was established by Shirk, et al. 2. They defined aeroelastic tailoring as "the embodiment of directional stiffness into an aircraft structural design to control aeroelastic deformation, static or dynamic, in such a fashion as to affect the aerodynamic and structural performance of that aircraft in a beneficial way." Further, Shirk, et al. 2 noted that the effectiveness of aeroelastic tailoring relies on the ability to control deformations and aerodynamic loads. This, in turn, necessitates the availability of an accurate aeroelastic simulation and materials which allow a versatile variation of cross-sectional stiffness properties.

Since the advent of composite materials, improvement of numerical methods, and recent availability of higher computing power, aircraft optimization via aeroelastic tailoring is now both possible and reasonably practical. However, a challenge lies in the optimization of not only one operating point, but in achieving performance increases over an operating spectrum. Sailplanes offer a unique opportunity to explore the aeroelastic tailoring process for a configuration that requires seemingly contradictory design requirements: reducing the induced drag for low speed, curved flight, and reducing airfoil drag at high speeds.

While such analyses have been conducted in practice before for unusual sailplane configurations, it is not commonplace during the design of production aircraft. For example, the very high aspect ratio and high wing loading of the Concordia sailplane [3] necessitated accounting for aeroelastic effects. Another numerical study by Sobieszanski-Sobieski and Haftka [4] analyzed the influence aeroelastic tailoring of a glider wing on the cross country speed and wing structural weight respectively. However, a $20 \mathrm{~m}$ wingspan glider is typically assumed to be rigid during the design phase. Thus, the performance impact of aeroelastic effects and the potential improvement via aeroelastic tailoring has remained largely unanswered for typical sailplane configurations.

This paper presents an aeroelastic simulation, the Modular Time-domain Aeroelastic Simulation (MTAS), which enables the simulation of static aeroelastic behavior of cantilever wings in low subsonic flow. Using this tool, a theoretical sailplane wing is analyzed and tailored to improve its average cross-country speed using the wing cross-sectional stiffness properties as a constraint.

\section{Sailplane Performance Metrics}

A typical mission profile for a sailplane differs greatly from those of other aircraft. While powered aircraft typically feature one design point at which they operate during cruise conditions, sailplanes must function efficiently across a wide spectrum. Evaluating a sailplane's performance therefore is a non-trivial task which necessitates accounting for low- and high speed straight flight, turn flight conditions, as well as the meteorological influence characterized by updrafts known as thermals. The following method is detailed by Thomas 5$]$ and will be presented in an abridged form.

\section{A. Steady Straight Flight Performance}

To analyze a sailplane's straight flight performance the aircraft is abstracted as a point mass and the equilibrium of forces are assessed (Fig. 1). Because a sailplane glides at an angle to maintain a constant speed, the lift is not perpendicular to the horizon axis, but rather tilted. The speed $v$ is determined using the equilibrium of vertical forces assuming horizontal flight.

$$
v=\sqrt{\frac{2 \cdot W}{\rho \cdot c_{L} \cdot S}}
$$

The sink rate can be obtained via the trigonometric relationship between airspeeds, linearized for small angles.

2 of 18

American Institute of Aeronautics and Astronautics 

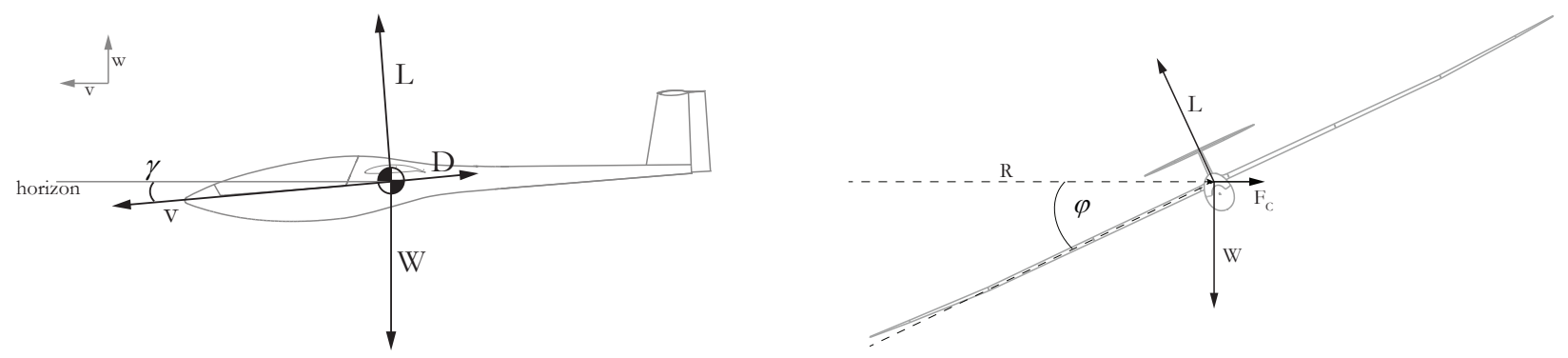

Figure 1. Equilibrium of forces for a sailplane in straight (left) and turned flight (right).

$$
\begin{aligned}
& \tan \gamma \approx \gamma=\frac{-w_{\text {straight }}}{v} \\
& w_{\text {straight }}=\gamma \cdot v \\
& w_{\text {straight }}=c_{D} \cdot c_{L}-\frac{3}{2} \cdot \sqrt{\frac{2 \cdot W}{\rho \cdot S}}
\end{aligned}
$$

Plotting the vertical sink rate over the horizontal airspeed results in the sailplane's speed polar (Fig. 2). This provides a metric for quantifying an aircraft's straight flight performance.

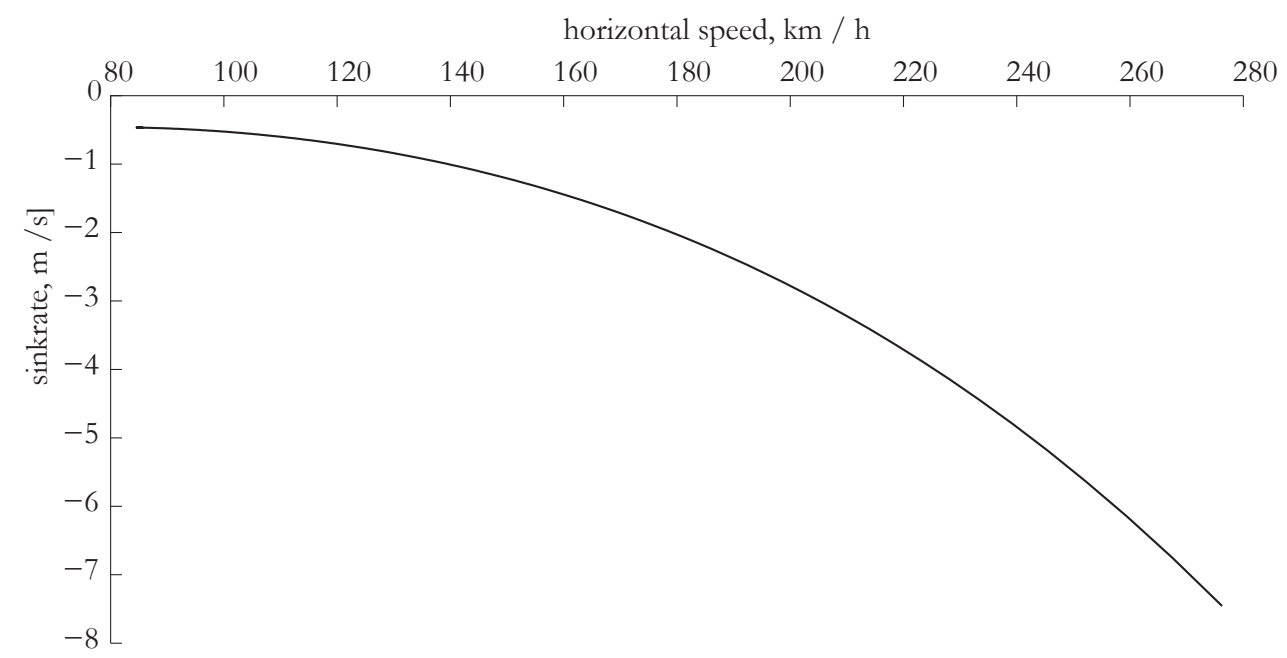

Figure 2. Speed polar for a sample sailplane.

\section{B. Steady Turn Performance}

Turned flight may be approximated by considering the aircraft as a point mass on a circular flight path. In this flight condition, the aircraft flies with a bank angle, so that the lift, weight, and centrifugal forces are in equilibrium (Fig. 1). The relationship between the centrifugal force, weight and lift are:

$$
\begin{aligned}
F_{C F} & =\frac{m \cdot v_{t u r n}{ }^{2}}{r} \\
W & =m \cdot g \\
W & =L \cos \phi \\
F_{C F} & =L \sin \phi
\end{aligned}
$$

$$
3 \text { of } 18
$$


The horizontal airspeed for turned flight is modified from the straight flight speed to account for the tilted lift vector and solved with the turn radius as a variable.

$$
\begin{aligned}
v_{\text {turn }} & =\sqrt{\frac{2 W}{\rho S c_{L} \cos \phi}} \\
w_{\text {turn }} & =c_{D} c_{L}{ }^{-\frac{3}{2}} \sqrt{\frac{2 W}{\rho S}}\left[1-\frac{2 W}{\rho S r g c_{L}}\right]^{-\frac{3}{4}}
\end{aligned}
$$

The influence of the turn radius on the horizontal airspeed is expressed by the relationship between the bank angle and the turn radius:

$$
\sin \phi=\frac{2 W}{\rho \operatorname{Srgc}_{L}}
$$

It should be noted, that the sink rate may be expressed as a function of the bank angle and the lift coefficient or the turn radius and the lift coefficient. As the thermal models are a function of their radius, the aircraft turn radius offers a more convenient variable than the bank angle for sailplane applications. Fig. 3 shows a turn polar as a function of the turn radius for the maximum lift coefficient of a sample sailplane configuration.

\section{Modeling Meteorological Conditions}

As sailplanes rely on thermals as their primary source of gaining altitude, a meteorological model has substantial influence on any performance analysis. An early model for the upwind distribution of thermals was proposed by Carmichael 6]. Carmichael postulated that a set of basic thermals - having a linear radial lift distribution and differentiated in width and strength (narrow/strong, narrow/weak, wide) — could be used to approximate the weather conditions met during cross-country flight. This model was refined by Horstmann [7] in the 1970s using insitu measurements. According to Horstmann's revision, four standard thermals are characteristic for middle European weather conditions (Fig. 3): narrow/weak (A1), narrow/strong (A2), wide/weak (B1), and wide/strong (B2). Because it appears to correlate more closely with the values encountered in nature [5], Horstmann's model is widely used today and is the basis of the presented calculations. Thus, the radial lift distribution of an arbitrary thermal can be expressed by a linear distribution with the strength (at $60 \mathrm{~m}$ ) and gradient given by Horstmann's data (Table 1 ).
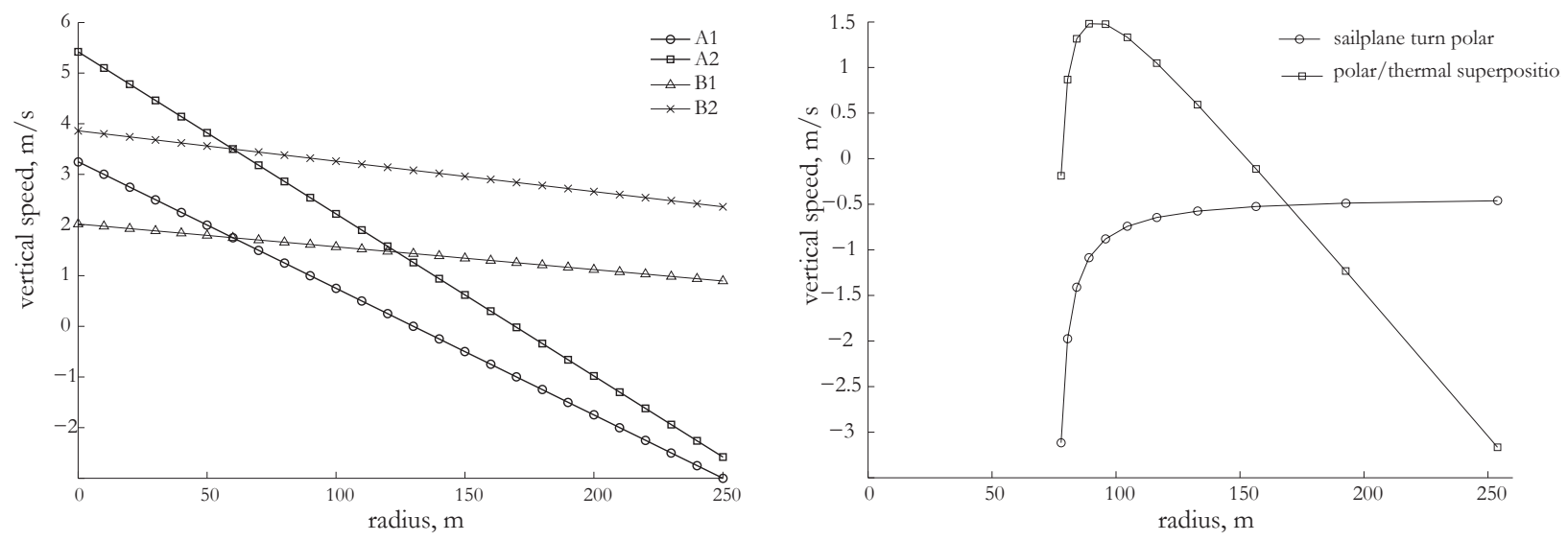

Figure 3. Radial distribution of the standardized Horstmann thermals (left) and the superposition between the turn polar and the upwind of a thermal (right).

$$
w_{\text {thermal }}=w_{60 m}-d w \cdot(R-60 m)
$$


Table 1. Characteristics of the standard thermals proposed by Horstmann 7 for European climatic conditions.

\begin{tabular}{lcccc}
\hline & A1 & A2 & B1 & B2 \\
\hline Thermal velocity at $r=60 \mathrm{~m}[\mathrm{~m} / \mathrm{s}]$ & 1.75 & 3.5 & 1.75 & 3.5 \\
Gradient $[1 / \mathrm{s}]$ & 0.025 & 0.032 & 0.0045 & 0.006 \\
Relative occurrence during flight & $8 \%$ & $42 \%$ & $8 \%$ & $42 \%$ \\
\hline
\end{tabular}

The relative rate of occurrence for these thermals was investigated by Quast [8]. He proposed that a typical $300 \mathrm{~km}$ flight may be characterized by four distinct phases: The early segment of the flight features predominantly narrow and weak thermals which transition into narrow and strong thermals. The second half of the flight offers wide and weak thermals which transition into wide and strong thermals toward the end of the flight.

Using this meteorological model, it is possible to predict the optimum climb rates for a given sailplane. Superimposing the thermal upwind distribution with the turn polar (expressed as a function of the lift coefficient and the turn radius) clearly indicates an optimum turn radius and climb rate for a given lift coefficient. The highest attainable climb speed is achieved at the maximum lift coefficient (Fig. 33).

\section{Cross-Country Theory}

Knowing the straight and turn flight performance as well as meteorological conditions alone is insufficient for evaluating sailplane performance. To determine performance a weighting mechanism is needed. As sailplanes are used for races, their performance is measured by their average cross country speed. This is expressed as the ratio between the total distance covered and the total flight time, which is the sum of the time spent during climb and gliding. During the design phase this speed is determined using the presented metereological model. A mission profile for a sailplane consists of turned flight during climb and straight flight during inter-thermal gliding (Fig. 4).

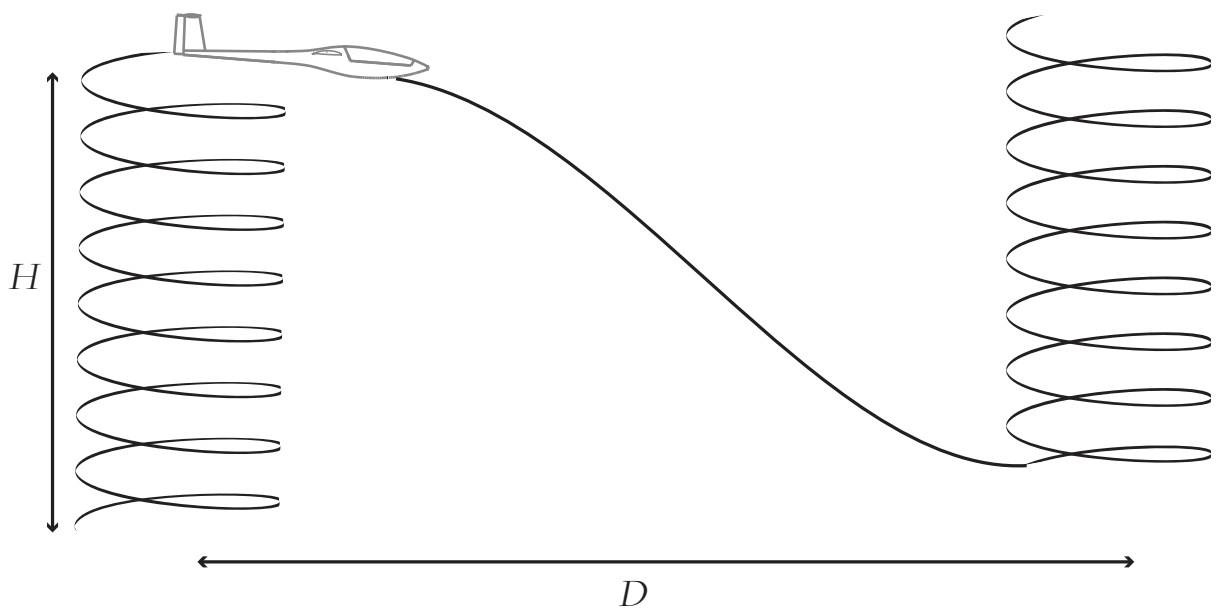

Figure 4. One segment of a typical cross-country flight. The sailplane gains altitude in thermals and subsequently covers distance while gliding.

$$
\begin{aligned}
v_{a v g} & =\frac{D}{t} \\
& =\frac{D}{t_{c}+t_{g}}
\end{aligned}
$$


Furthermore, the time needed to climb or glide can be evaluated using the sink rates already obtained during the straight and turned flight analyses:

$$
\begin{aligned}
t_{c} & =\frac{H}{w_{c}} \\
t_{g} & =\frac{H}{w_{\text {straight }}}
\end{aligned}
$$

Using the angular relation between the straight flight speeds and the height and distance, the average flight speed (or cross-country speed) can be calculated as a function of the horizontal glide speed, climb rate, and straight flight sink rate:

$$
\begin{aligned}
& D=\frac{v_{\text {glide }}}{w_{\text {straight }}} H \\
& v_{\text {avg }}=\frac{w_{c}}{w_{c}+w_{\text {straight }}} v_{\text {glide }}
\end{aligned}
$$

The climb rate, as discussed, is the superposition of the thermal lift distribution and the turn polar:

$$
w_{c}=w_{\text {thermal }}-w_{\text {turn }}
$$

Using the established equations for the straight flight and turned flight sink rates as well as the horizontal glide speed, the cross-country speed can be calculated and an optimum for the given configuration determined. If the drag coefficient is an analytical function of the lift coefficient this optimization corresponds to determining the zeroes of the differentiated average cross country speed:

$$
\frac{d v_{a v g}}{d c_{L}}=0
$$

This analysis must be conducted for each of the four phases of the flight as defined by Quast 8 . Thereafter, the total average speed is determined as the weighted mean between the cross-country speed of all four flight segments.

Furthermore, the cross-country speed is a metric used during the design process, which not only offers the designer a glimpse of the aircraft's potential, but also serves as an objective function for design optimization. Clearly, a pilot would be unable to attain such performance under identical conditions, as the model assumes optimal decision making and perfect choice of speeds, turn radii, angle of attack, etc. Additionally, the calculated average speed does not represent the highest achievable speed; weather conditions will deviate from the model used and thus increase or decrease the achievable cross-country speed accordingly.

\section{E. Aeroelastic Optimization of Cross-Country Speed}

In the absence of an analytical correlation between the lift and drag coefficients - the lift and drag coefficients are calculated numerically - the optimum cross-country speed must be determined by a comparison of discrete values. The operational spectrum is discretized and the cross-country speed is determined for each point. The optimum cross-country becomes the highest value determined in this fashion.

The optimization of the flexible sailplane requires an aeroelastic analysis to map the entire operational spectrum. The lift and drag for the deformed geometry is numerically calculated and the optimum crosscountry speed (for the deformed state) determined as presented. The cross-country speed now serves as the objective function for the aeroelastic tailoring process, with the cross sectional flexibility as the design variables. Thus, the optimization is an iterative process which involves aeroelastic analysis and modification of stiffness properties to adjust wing deflections at various operating points (Fig. 5). 


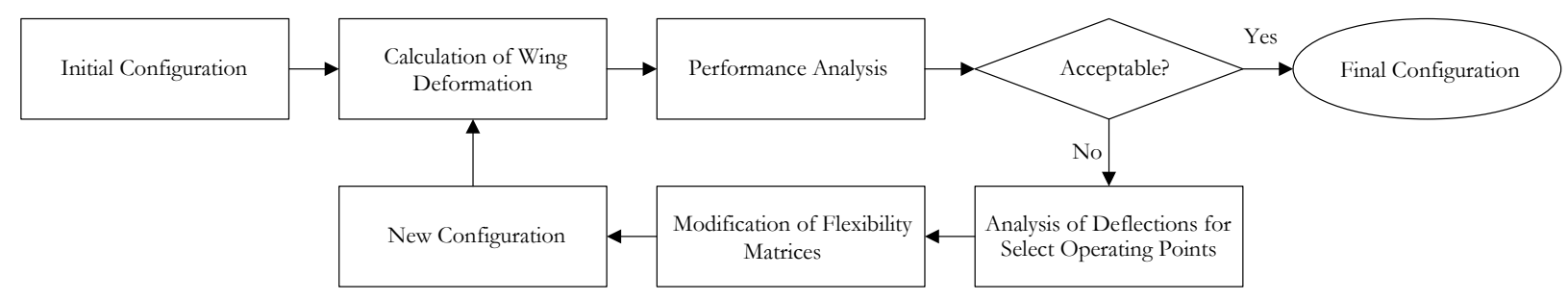

Figure 5. Block diagram of the aeroelastic optimization process.

\section{Aeroelastic Simulation}

The aeroelastic simulation couples a nonlinear quasi three-dimensional beam solver with a three-dimensional, inviscid panel method. Viscous drag is accounted for via two-dimensional airfoil drag polars. Instead of simulating the entire wing geometry, symmetry about the y-z plane is used to reduce computational expense. Figure 6 illustrates the interaction between the structural and aerodynamic solvers.

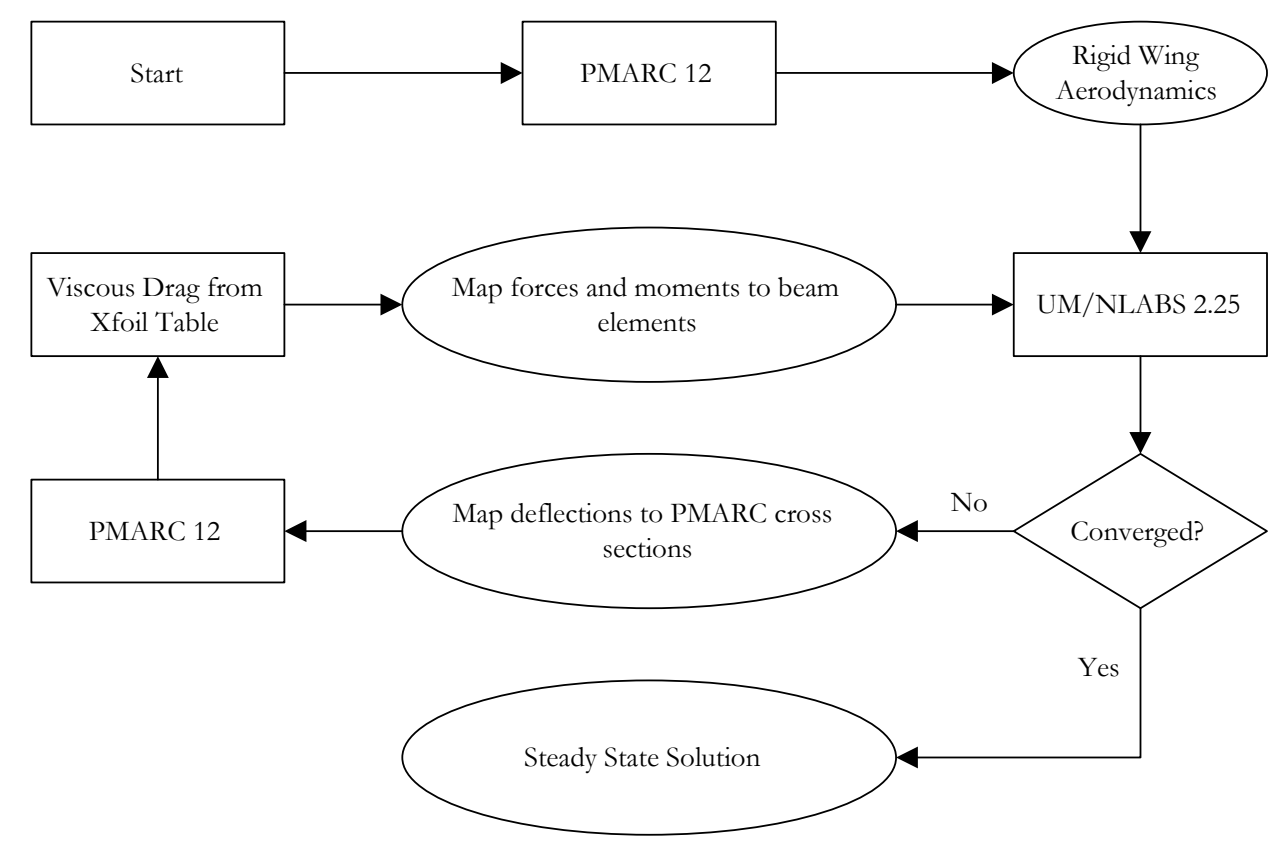

Figure 6. Block diagram of the interaction between the aerodynamic and structural solvers in MTAS.

Every structural element is assigned a column of aerodynamic panels (and vice versa). Deflections and rotations are calculated at the structural nodes, which correspond to the panel boundaries of the aerodynamic solver. After deflections are passed to the aerodynamic routines, the aerodynamic cross-section coordinates are transformed to obtain a deflected and paneled aerodynamic model for further analysis.

Global time steps are subdivided into aerodynamic and structural time steps. A global time interval begins with the aerodynamic simulation of the wing geometry. The aerodynamics routine runs a user-specified amount of independent time steps, beginning at $t=0$ and no initial wake, and collates the aerodynamic coefficients for the last aerodynamic time step only. All coefficients are transitioned into aerodynamic forces and moments and transformed into the body coordinate system. Utilizing the aerodynamic loads, the structural solver runs its time-stepped simulation. Once the structural routine has completed a predefined set of time steps, the node deflections and rotations are retrieved. This data, in turn, is passed on to the aerodynamic routine, to initiate the next global time step. 


\section{A. Aerodynamics}

The aerodynamic solver couples the three-dimensional panel method Panel Method Ames Research Center (PMARC) [9] with the two-dimensional calculations of XFOIL [10.

PMARC 12 was developed by NASA at the Ames Research Center in the early 1990s. It is a threedimensional panel code, which incorporates an option for a flexible wake to study unsteady aerodynamic effects. Patches are defined by cross sections; the number of panels in span direction are specified between these sections. For this aeroelastic analysis, however, the cross sections form the border of the panels, so that curvatures of the deflected geometry may be mapped accurately.

XFOIL was developed at MIT by Mark Drela in the 1980s. It is a design and analysis tool for two dimensional airfoil sections. XFOIL incorporates both an inviscid and a viscous panel method capable of predicting turbulent transition. Although XFOIL offers several design routines, MTAS only utilizes its viscous analysis capabilities.

Whereas PMARC accounts for the three-dimensional flow affects and their influence on the pressure distribution and induced drag, XFOIL is used to approximate the viscous wing drag contribution. Once PMARC's simulation has completed, the aerodynamic coefficients are retrieved. In addition to global lift, moment and drag coefficients, PMARC also outputs the aerodynamic coefficients for each column of panels. The section lift coefficient is used to interpolate the airfoil drag via lookup tables calculated by XFOIL during simulation preprocessing.

Naturally, due to the two-dimensional nature of XFOIL, three-dimensional viscous effects cannot be assessed. For high aspect ratio wings of moderate sweep, however, the viscous boundary layer becomes two-dimensional in nature and therefore lends credence to this approach.

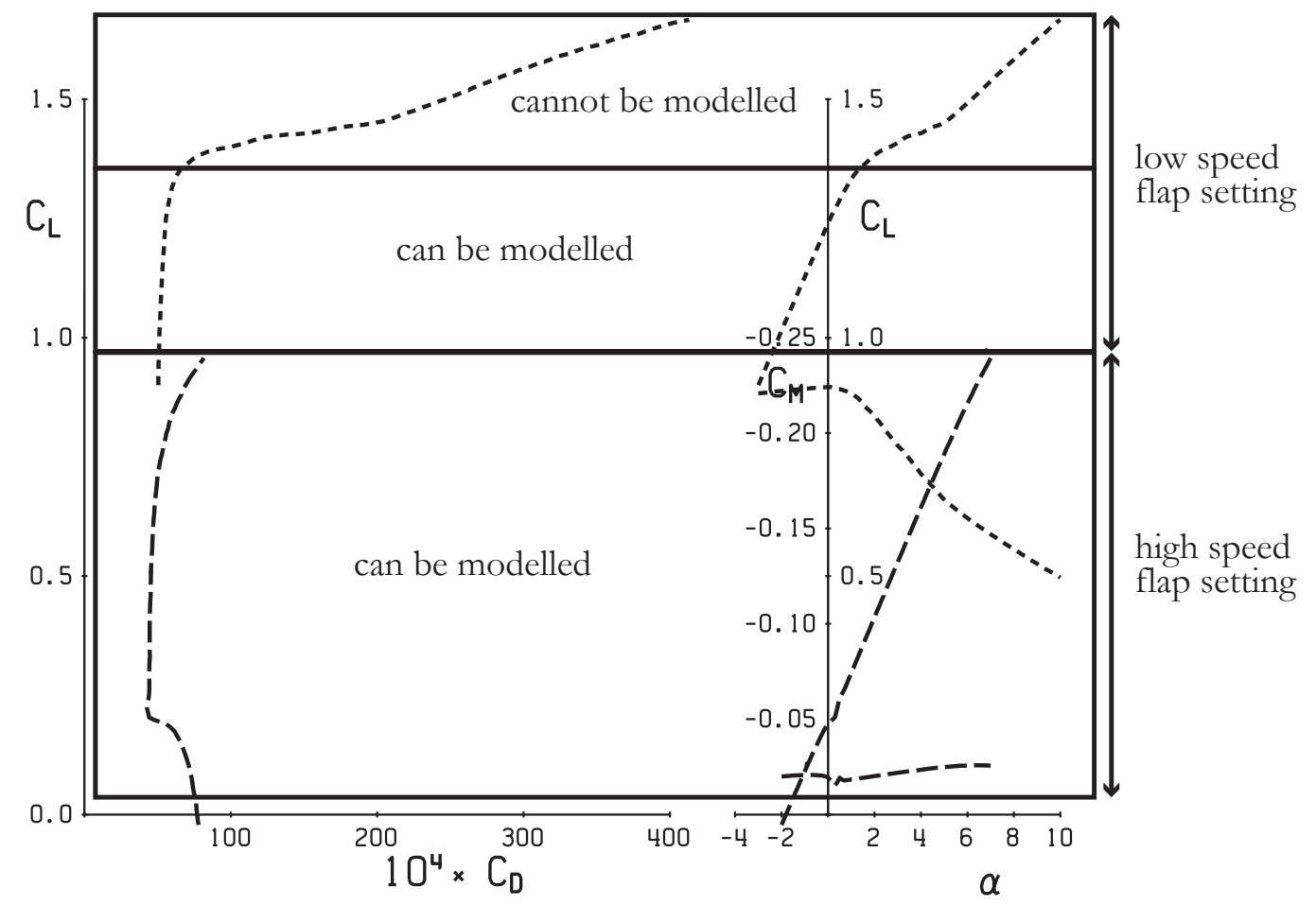

Figure 7. Limitations of the aeroelastic simulation. While the entire high speed flap setting can be modeled, the low speed setting can only be modeled in part.

In addition to the section coefficients, the induced drag is accounted by adding it to the drag coefficient 
of the last element of the wing. Using the aerodynamic coefficients, the total forces and moments which act on each structural element (or column of aerodynamic panels) are calculated.

Both PMARC and XFOIL offer faster solution speeds than three-dimensional CFD codes, whose computational expense are an order of magnitude higher. Despite having a performance advantage, PMARC - as a potential flow code - only models the linear portion of the lift curve. Figure 7 depicts the high and low speed flap setting for a sailplane airfoil. While the high speed setting can be modeled completely, the low speed setting can only be modeled until the point at which the airfoil stalls. To model post-stall behavior, modifications or other tools such as CFD are necessary. Most analyses, however, do not need to account for post-stall conditions, as stall conditions are generally avoided.

\section{B. Structure}

Structural conditions are simulated using a quasi three-dimensional finite element beam solver, UM/NLABS 2.25 (Non-Linear Active Beam Solver), which was developed at the University of Michigan by Palacios and Cesnik 11]. Aerodynamic loads are submitted to UM/NLABS along with structural boundary conditions, stiffness, and mass parameters. Each beam is defined as a member, the i-th member consisting of $N_{i}$ finite elements. Cross-section stiffness and mass properties are defined at the ends of each member (Fig. 8). The stiffness and mass matrices for the elements between the ends are interpolated linearly. An additional code developed in tandem with UM/NLABS, Variational Asymptotic Beam Section Analysis (UM/VABS) [12, is used to determine the stiffness and mass properties for a given cross section.

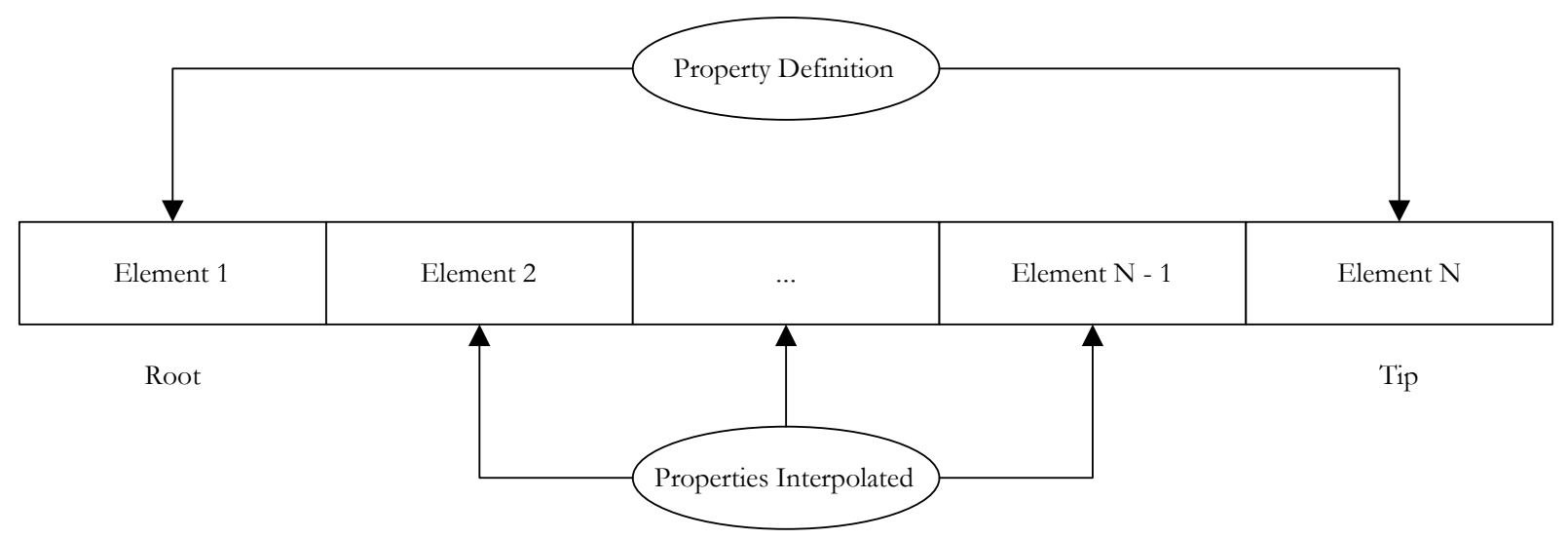

Figure 8. Property definition along a member beam.

To achieve a steady state solution, a very large time interval is chosen for UM/NLABS. A wing is structurally modeled as a series of beams along the $25 \%$ chord line. Any variations in wing section sweep, taper, or discretization results in the definition of an individual beam. The first member in this set is clamped at its root. The last beam has an unconstrained tip, and all intermediate ends match displacements and rotations at the boundaries between individual beams.

\section{Analyzing Multiple Operating Points}

To assess multiple operation points, the analysis must be divided into several sub-simulations, each encompassing a single operating point. If, for example, $N$ angles of attack and $M$ airspeeds are provided to be analyzed, a total of $N \times M$ operating points must be simulated individually. In the case of a sailplane, points within that space are interpolated to satisfy the steady flight conditions. 


\section{Composite Material Properties}

To simplify the determination of material properties a number of simplifications can be made. Instead of describing the layup with all of its intertwined fibers, the entire layup is decomposed into individual unidirectional fiber layers (Fig. 9). Furthermore, within the layup individual composite layers are modelled as homogenous orthotropic material with the representative mechanical characteristics. To achieve this, the mechanical properties of the fibers and the matrix system must be known and are combined using the mixture rules as detailed by Schuerman 13]:

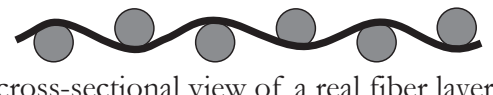

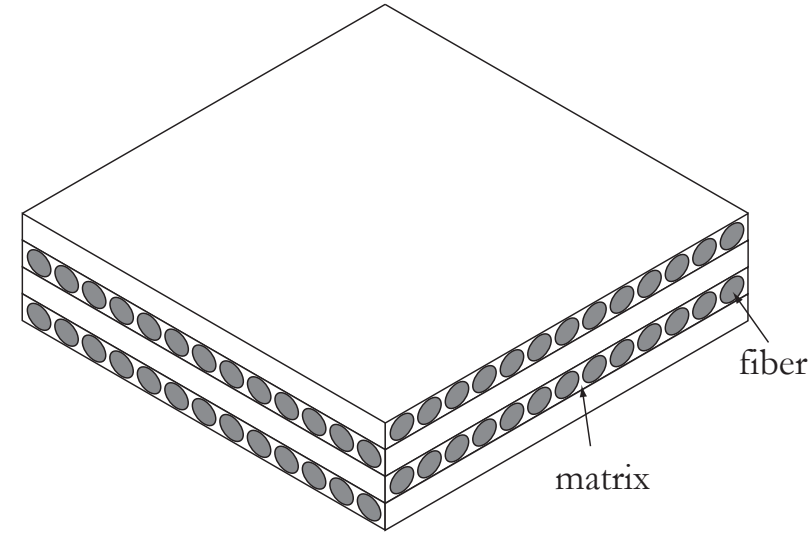

idealisation of a composite layup

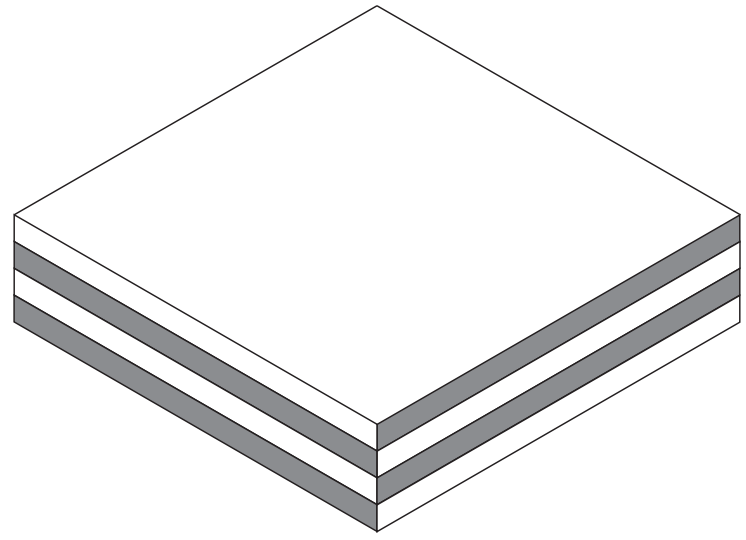

idealisation of as a stacked orthotropic material

Figure 9. Steps for idealizing a multiple ply composite layup.

$$
\begin{aligned}
& E_{\|}=E_{f \|} \cdot \varphi+E_{m} \cdot(1-\varphi) \\
& E_{\perp}=\frac{E_{m}}{1-\nu_{m}^{2}} \cdot \frac{1}{(1-\varphi)+\frac{E_{m}}{\left(1-\nu_{m}^{2}\right) \cdot E_{f \perp}} \cdot \varphi} \\
& G_{\perp \|}=G_{m} \cdot \frac{1}{(1-\varphi)+\frac{G_{m}}{G_{f \perp \|}} \cdot \varphi} \\
& \nu_{\perp \|}=\varphi \nu_{f \|}+(1-\varphi) \cdot \nu_{m} \\
& \nu_{\| \perp}=\frac{\nu_{\perp \|}}{E_{\|}} \cdot E_{\perp} \\
& \nu_{m, e f f}=\nu_{m} \cdot \frac{1+\nu_{m}-\nu_{\perp \|} \cdot \frac{E_{m}}{E_{\|}}}{1-\nu_{m}^{2}+\nu_{m} \cdot \nu_{\perp \|} \cdot \frac{E_{m}}{E_{\|}}} \\
& \nu_{\perp \perp}=\varphi \cdot \nu_{f}+(1-\varphi) \cdot \nu_{m, e f f} \\
& G_{\perp \perp}=\frac{E_{\perp}}{2\left(1+\nu_{\perp \perp}\right)}
\end{aligned}
$$

However, as noted by Schuerman [13, some of the theoretical values obtained in this manner do not correspond to experimental data. Puck 14 as well as Foerstner and Knappe 15 formulated empirical formulae for the Young's and shear modulus respectively, which correlate more closely to experimental data 13]. 


$$
\begin{aligned}
& E_{\perp}=\frac{E_{m}}{1-\nu_{m}^{2}} \cdot \frac{1+0.85 \cdot \varphi^{2}}{(1-\varphi)^{1.25}+\frac{E_{m}}{\left(1-\nu_{m}^{2}\right) \cdot E_{f \perp}} \cdot \varphi} \\
& G_{\perp \|}=G_{m} \cdot \frac{1+0.4 \cdot \varphi^{0.5}}{(1-\varphi)^{1.45}+\frac{G_{m}}{G_{f \perp \|}} \cdot \varphi}
\end{aligned}
$$

These equations are used to determine the composite material properties for a single unidirectional layer based on typical fiber and matrix data. The fiber volume content $\varphi$ is set to a conservative value of 0.5 which correlates to a hand wet in wet lamination technique. Finally, the entire fiber layup is used to create the base structural configuration.

\section{Code Verification}

To assess the validity of the aeroelastic simulation, published results for a theoretical, very flexible HALE wing are used as a benchmark. The NACA 0012 HALE configuration utilized by Smith, et al. [16] and Hallissy and Cesnik [17 features a wing span of $32 m$ and a uniform chord length of $1 m$ with no sweep. The wing parameters and flight properties are listed in tables $2-3.17$.

Table 2. Geometric, structural and mass properties of the NACA 0012 HALE configuration.

\begin{tabular}{lc}
\hline Property & Value \\
\hline Semi-span & $16 \mathrm{~m}$ \\
Chord & $1 \mathrm{~m}$ \\
Elastic Axis & $0.5 \mathrm{c}$ \\
Center of Gravity & $0.5 \mathrm{c}$ \\
Mass / Span & $0.75 \mathrm{~kg} / \mathrm{m}$ \\
Inertia about mid-chord & $0.1 \mathrm{kgm}$ \\
Torsional $(\mathrm{GJ})$ & $1.0 \times 10^{4} \mathrm{Nm}^{2}$ \\
Bending $\left(\mathrm{EI}_{2}\right)$ & $2.0 \times 10^{4} \mathrm{Nm}^{2}$ \\
Edgewise Bending $\left(\mathrm{EI}_{3}\right)$ & $5.0 \times 10^{6} \mathrm{Nm}^{2}$ \\
\hline
\end{tabular}

Table 3. Flight conditions for the NACA 0012 HALE configuration.

\begin{tabular}{lc}
\hline Property & Value \\
\hline Altitude & $20 \mathrm{~km}$ \\
Density & $0.0889 \mathrm{~kg} / \mathrm{m}^{3}$ \\
Angle of Attack & $2 \mathrm{deg}$ \\
Reynolds Number & 154,550 \\
\hline
\end{tabular}

\section{A. Numerical Results}

The simulation shows fast convergence (3 iterations). Bending is overpredicted by approximately 10 percent compared to the Euler code used in Smith, et al. 16, placing the results in the vicinity of the HiFi VFA Euler and Navier Stokes values and lower than the UM/NAST 1820 results presented by Hallissy and Cesnik [17] (Fig. 10p). A similar trend is seen for the twist angle, where MTAS overpredicts Smith et al. by approximately 5 percent and also lies between the Euler/Navier Stokes and UM/NAST codes. Given the proximity of the MTAS results to the references, it appears to be well suited for simulating high aspect ratio wings in laminar flow conditions. 

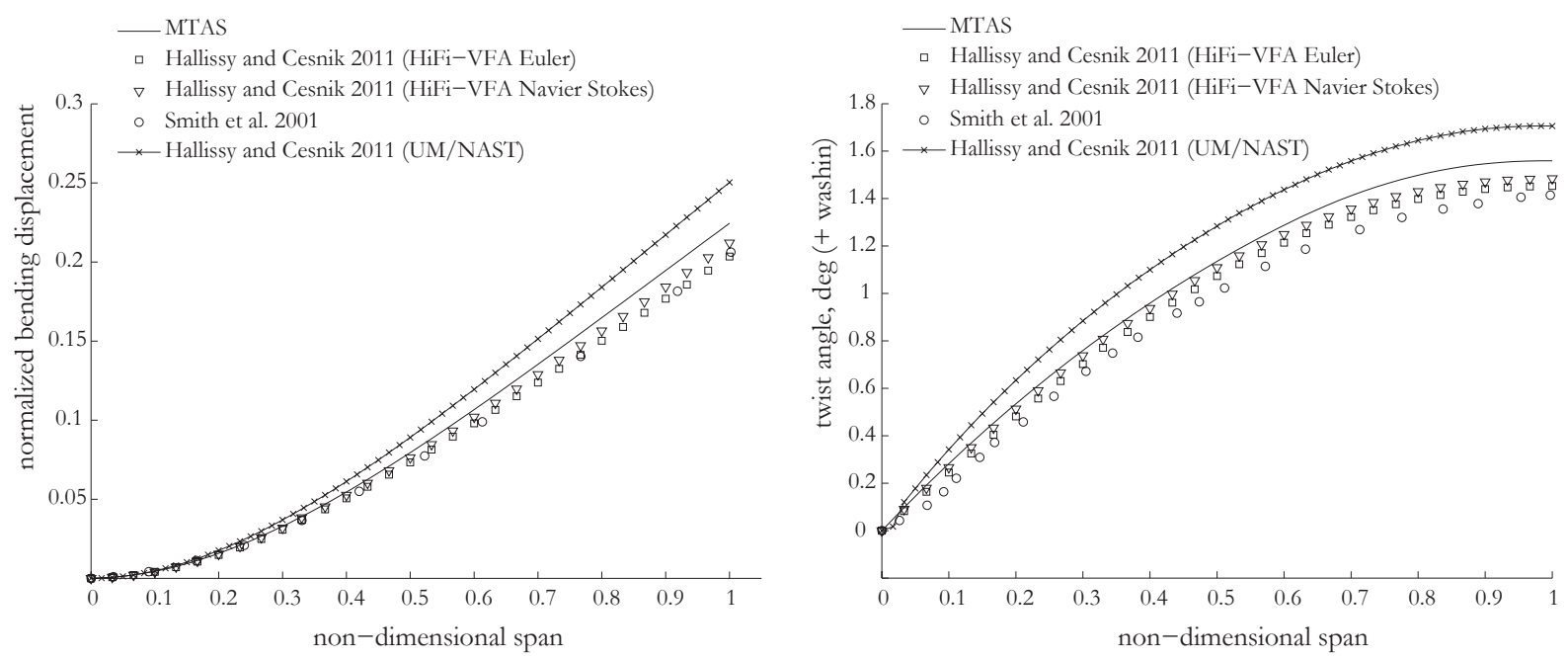

Figure 10. Comparison of the numerical results for the NACA 0012 HALE test configuration.

\section{Aeroelastic Tailoring}

For the purpose of this research, a theoretical sailplane configuration, the ARW-1 (Fig. 11), was designed to demonstrate the aeroelastic optimization process for applications with a wide operational spectrum. While the performance characteristics mirror those of modern sailplanes, the airworthiness requirements for structural strength, as mandated by the CS-22, were not analyzed or observed. The purpose of this configuration is to provide a qualitative assessment of the possibilities enabled by aeroelastic tailoring rather than arriving at a certifiable aircraft design.

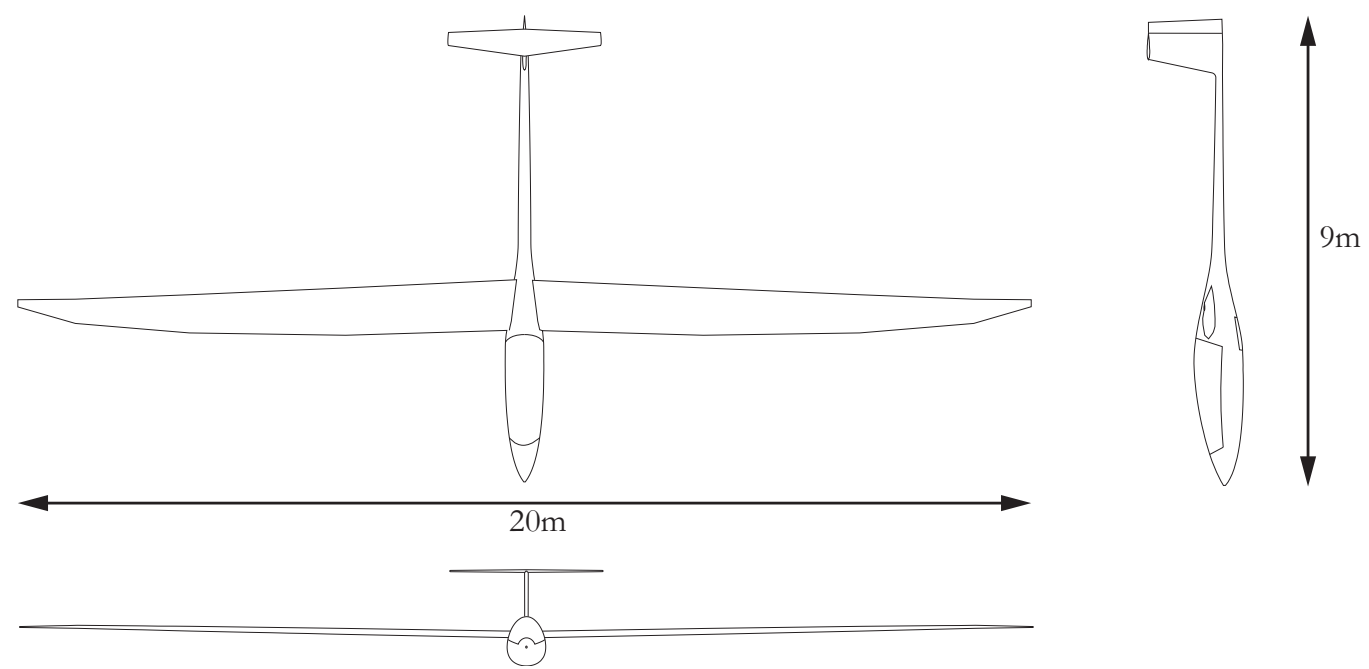

Figure 11. Three-side view of the ARW-1 sailplane configuration.

\section{A. ARW-1 Configuration}

The ARW-1 is a dual-seat sailplane with a wing span of $20 \mathrm{~m}$. It conforms to the FAI $20 \mathrm{~m}$ (dual-place) competition classification and fulfills the airworthiness requirements with respect to performance. To increase performance multiple airfoils are used at varying span locations lowering airfoil drag and for the rigid wing and ensuring benign stall behavior. 
The wing is structurally modeled as a beam along the $25 \%$ chord line and the aerodynamic model is defined by the airfoil cross sections (Fig. 12). Structural and mass properties of the individual cross sections are calculated by UM/VABS for the base configuration.
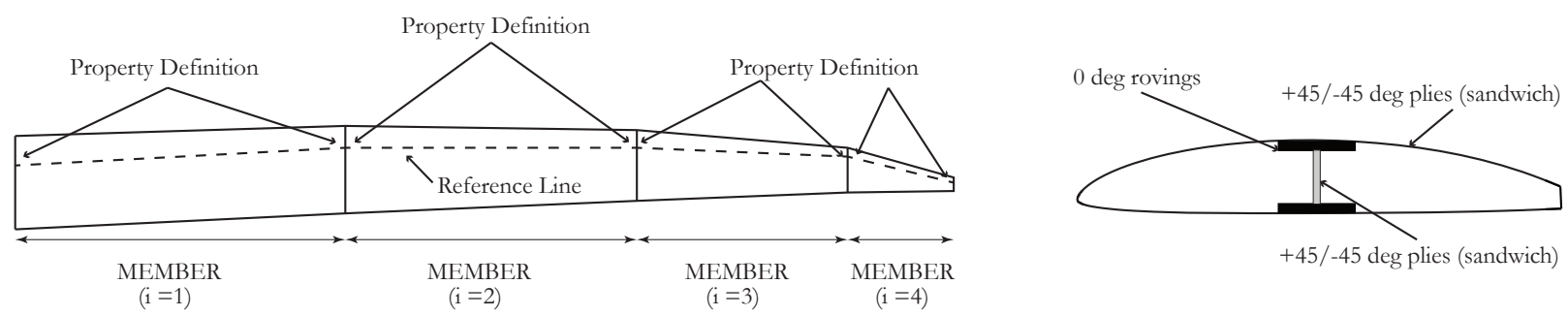

Figure 12. Structural simplification of the ARW-1 wing (left). The wing is modeled as a series of beams along the 25 percent chord line. The stiffness properties for the initial configuration are determined using UM/VABS on a typical sailplane cross section (right).

The ARW-1 wing structure consists of two parts: the wing spar, which accounts for most of the bending stiffness and the wing skin, which accounts for the torsional rigidity. The wing spar features two flanges made of carbon fiber rovings, and the shear web, which is manufactured with $+45 /-45$ degree carbon fiber (twill) plies. The wing skin - in the initial configuration - consists of 12 carbon fiber plies (twill) with $+45 /-45$ degree orientation (Fig. 12).

\section{B. Optimization}

The aeroelastic optimization process uses the cross country speed as the objective function while the cross section flexibility matrices serve as design variables. To reduce the number of variables, properties are defined at the edges of a member (Fig. 12 with the intermediate properties interpolated linearly. A further reduction in design variables is achieved by only varying bend-twist coupling and bending flexibility terms. To simplify the manual optimization process only homogeneous changes to the flexibility changes were made, i.e., changes were only made to bending-twist coupling or bending flexibility during one iteration step. Furthermore, the largest permissible change is constrained for each wing section (definiton, see Fig. 12), varying from $5 \%$ for the inboard section to $30 \%$ for the outboard wing section. Finally, the optimized configuration must have a divergence speed that is larger than the maximum speed in the glider's flight envelope. Thus, the optimization problem is:

$$
\max \left[v_{a v g}\left(K_{i}^{-1}\right)\right]
$$

subject to:

$$
\begin{aligned}
& \left|\Delta K_{i}^{-1}\right| \leq \bar{k}_{i}\left|K_{\text {base }, i}^{-1}\right|, i=1, . ., 4 \\
& v_{\text {div }}>v_{\max }
\end{aligned}
$$

where:

$$
\begin{aligned}
& \bar{k}_{1}=0.05 \\
& \bar{k}_{2}=0.10 \\
& \bar{k}_{3}=0.20 \\
& \bar{k}_{4}=0.30
\end{aligned}
$$

\section{Rigid Aircraft and Base Configuration Analysis}

The performance of the rigid aircraft is determined according to cross country theory using aerodynamic results from MTAS for the undeflected wing. The resulting geometric and performance data for the ARW-1 
are given in Table 4. The straight and turned flight as well as cross-country performance were determined for maximum wing loading conditions.

Table 4. ARW-1 geometry and rigid performance data.

\begin{tabular}{lc}
\hline Property & Value \\
\hline Wing Span & $20 \mathrm{~m}$ \\
Wing Surface Area & $13.6 \mathrm{~m}^{2}$ \\
min. Sink Rate & $<0.5 \mathrm{~m} / \mathrm{s}$ \\
Cross Country Speed & $36.6 \mathrm{~m} / \mathrm{s}$ \\
\hline
\end{tabular}

Whereas the rigid aircraft serves as a benchmark, the initial configuration and its aeroelastic performance offer a more significant comparison: The performance of the flexible aircraft represents the real world performance. Additionally, the base configuration offers a comparison to current production sailplanes, as it reflects the status quo in sailplane wing manufacturing.

Figure 13 summarizes the displacements and performance for the initial configuration. The tip twist angle varies between 0.5 and 0.9 degrees with the largest angle occuring during high speed flight. It is of note that the cross country speed for this configuration increases to $38.5 \mathrm{~m} / \mathrm{s}$ compared to the rigid wing, despite the increase in twist.
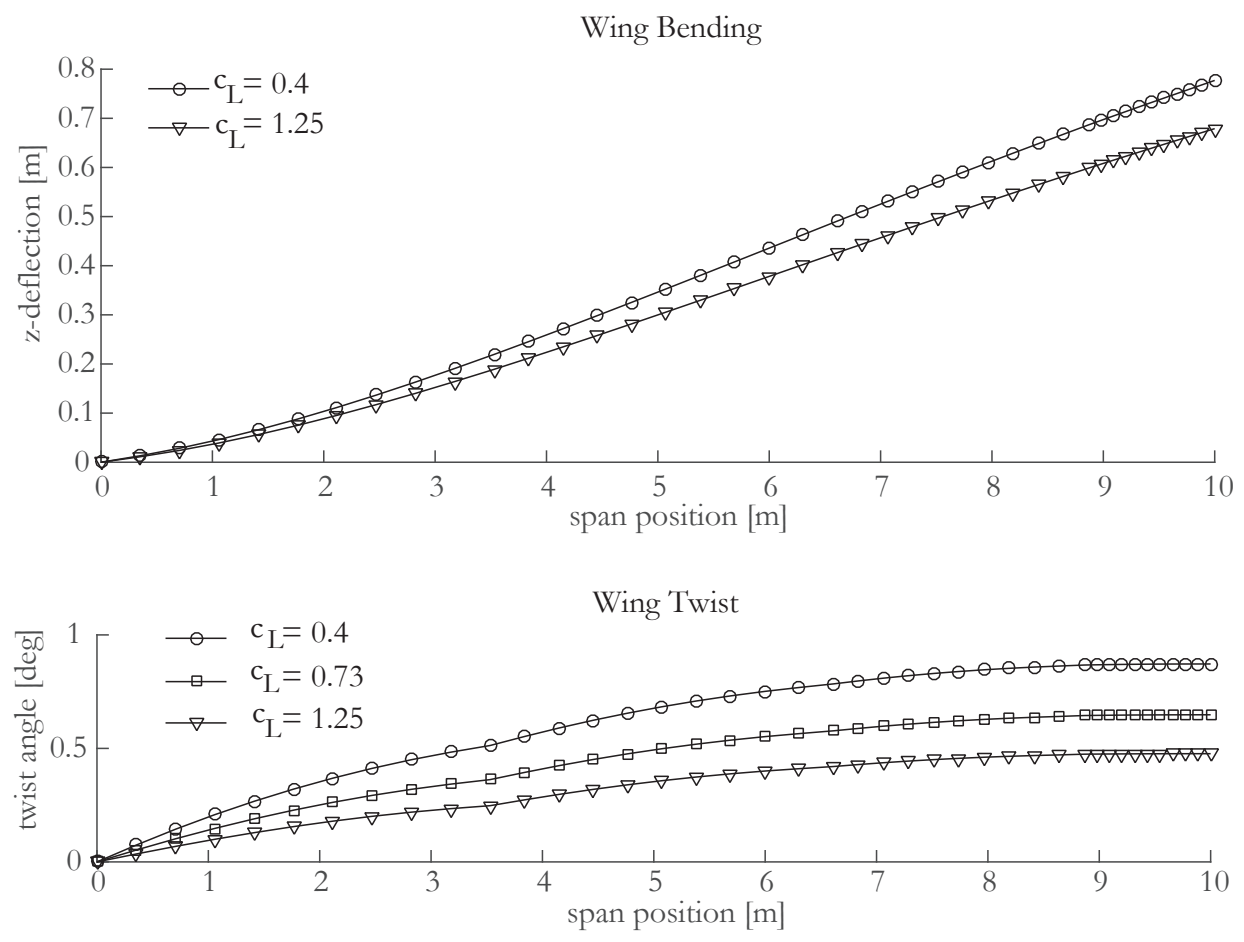

Figure 13. Twist and bending deformation for the ARW-1 in base configuration.

\section{Optimized Configuration}

Multiple optimization paths were attempted, including modifying torsion, bending and twist-bending (coupled) stifnesses. While each path increases the cross-country speed compared to the base configuration, the best solution is obtained by a combination of all changes (Fig. 14). Reducing torsional rigidity by $15 \%$ yielded the highest increase in cross-country speed (of all torsional configurations), while an increase rigidity 
led to a performance penalty compared to the base configuration. A reduction in out of plane bending stiffness resulted in an increase in cross-country speed similar to the reduction in torsional rigidity. Modest gains compared to the base configuration are achieved by increasing the coupling between bending and torsion. The final, improved configuration is attained by combining the optimal result for reduced torsional rigidity and lowering bending stiffness while increasing bending-torsion coupling (Fig. 15). Figure 14 shows the progression from combining reduced bending, torsional, and increasing the coupling of bending and twist (combinations 1-3). While increasing twist-bending coupling initially increases the cross-country speed, a drop-off in cross-country speed can be noted in combination 3, which features greatest coupling.

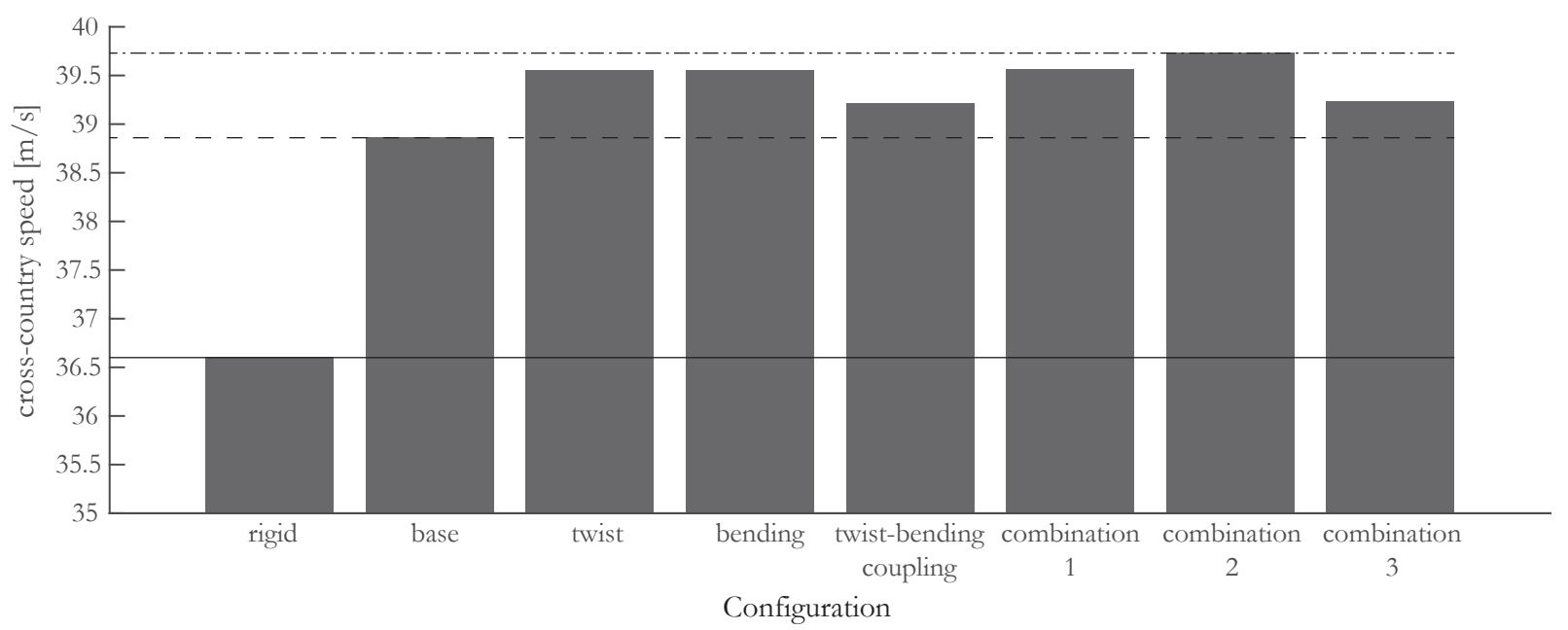

Figure 14. Cross-country performance across the optimization progression.

The final configuration yields a cross-country speed of $39.73 \mathrm{~m} / \mathrm{s}$, more than $1 \mathrm{~m} / \mathrm{s}$ faster than the base configuration and more than $3 \mathrm{~m} / \mathrm{s}$ faster than the rigid wing. Simultaneously, the peak aerodynamic efficiency of the final configuration is lower than the base configuration. While this may appear contradictory, a comparison of the speed polars for the base and final configurations (Fig. 16) shows that the final version does outperform the base configuration significantly in parts of the flight envelope. Thus, while the base configuration maintains an incremental advantage in high speed flight, the final version outweighs this by improving mid-speed performance. Similarly, the final wing outperforms the base configuration during climb for all except the B2 thermals. As a result, the sum of these improvements outweighs the reduction in peak aerodynamic performance and can be translated to a tangible advantage during race conditions. 

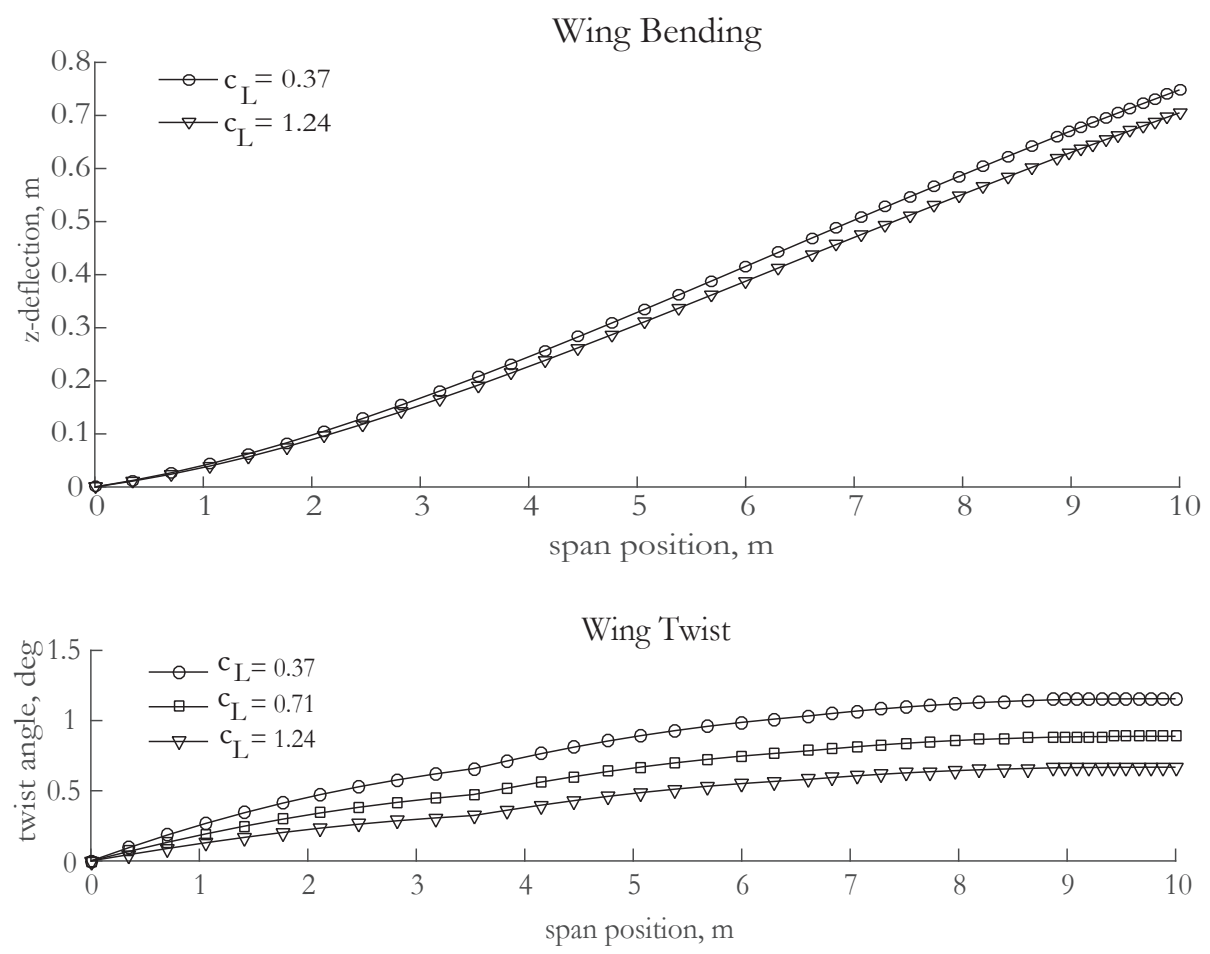

Figure 15. Twist and bending deformation for final configuration.

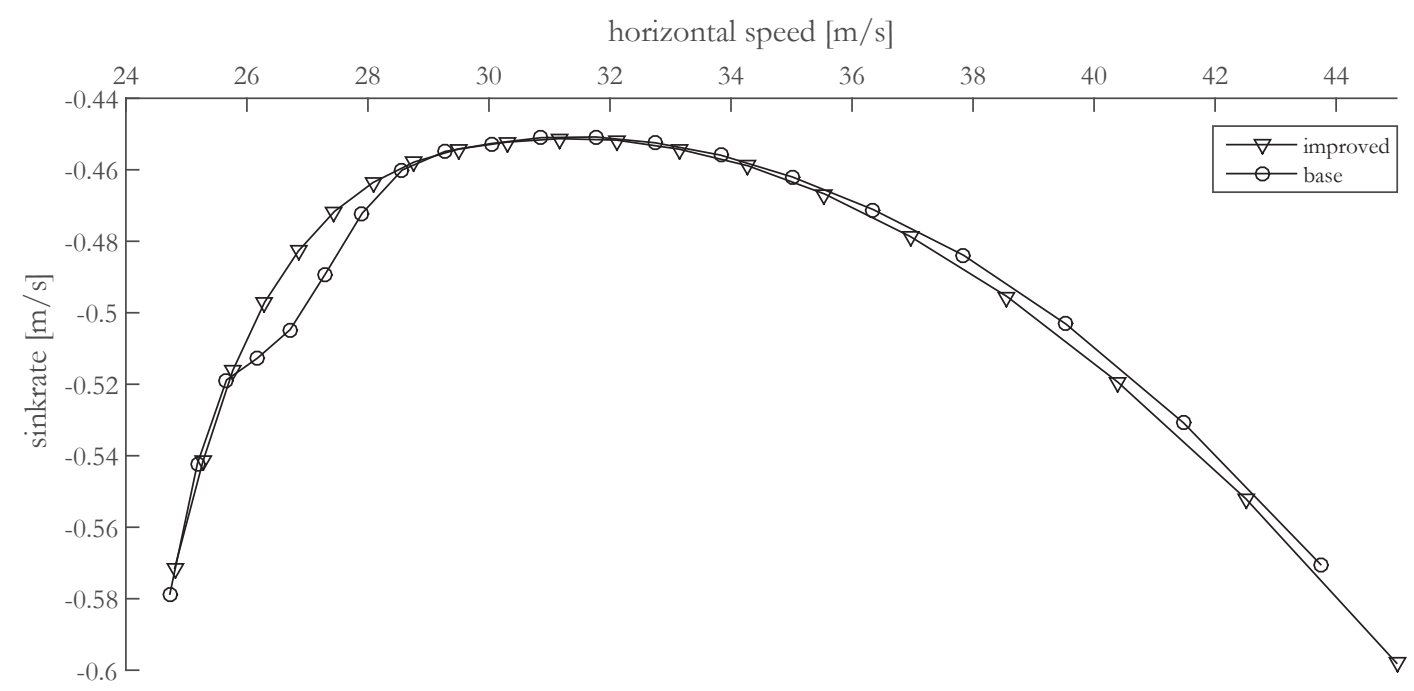

Figure 16. Comparison of the speed polars for the base (flexible) and the improved configurations.

\section{Concluding Remarks}

An aeroelastic simulation tool, MTAS, was created to facilitate aero-structural improvement of anisotropic wings in low speed flow. The aeroelastic simulation was verified using a published configuration. Numerical results from the aeroelastic simulation correlate closely to the reference cases. Additionally, the MTAS simulations converge needing few iteration steps, thus reducing the total simulation time and enabling rapid aeroelastic design iterations. 
Subsequently, a conceptual sailplane configuration, the ARW-1, was optimized with respect to its crosscountry performance. Both the rigid wing and flexible base configuration served as reference values during the optimization process. While the base configuration already improves the cross-country speed by approximately $2 \mathrm{~m} / \mathrm{s}$, a further increase in average speed of $1 \mathrm{~m} / \mathrm{s}$ was achieved by varying cross sectional stiffness properties.

The improved configuration features reduced torsional and bending stiffnesses. While no inverse determination of the fiber layup was conducted, the changes to base configuration reflect a combination of structural changes: The reduction in bending rigidity corresponds to a downsizing of the wing main spar. Particularly the outboard section was affected by this change with a reduction of bending stiffness by $30 \%$ of the baseline value. This is possible, because the baseline wing has continuous rovings from the root to the tip of the wing. Consequently, the outboard section is unnecessarily stiff. Increased coupling may be achieved by rotating ply angles, moving the spar position or a combination of both. Meanwhile, a reduction in torsional rigidity may be the result of the modification of ply angles.

The result of most of these modifications, with the exception of the varying of ply angles or spar position, is a potential reduction in wing structural mass, though the presented analysis cannot quantify to what extent. While a reduction in wing structural mass does not inherently benefit the aircraft's cross-country speed, this mass reduction can be reinvested into a higher aspect ratio wing, a metric that tangibly increases cross-country performance. An alternative to this is to compensate the mass reduction with water ballast, giving the pilot additional flexibility to adapt to varying weather conditions.

The achieved results resemble those of Sobieszanski-Sobieski and Haftka [4]. The optimization SobieszanskiSobieski and Haftka conducted resulted in an incremental increase of $1 \%$ in cross-country speed due to using integrated design over the compartmental method. The final design presented here corresponds to a performance increase of $2.6 \%$. The difference in performance gain is a result of the presented optimization varying the anisotropic properties of the wing, while Sobieszanski-Sobieski and Haftka did not allow a change in ply orientation or reduction/addition of plies. Furthermore, while one or two percent may appear to be meager increases in performance, in the case of the ARW-1 this translates to a four minute advantage for the optimized wing over the base configuration on a typical $300 \mathrm{~km}$ race task.

The optimization process represents a shift away from compartmental towards integrated design as described by Sobieszanski-Sobieski and Haftka 4]. Structural and aerodynamic performance are no longer analyzed separately, but are now an iterative process. The ARW-1 example illustrates the gains that can be made using this technique. However, to fully utilize the aeroelastic optimization in the design process an inverse method for determining the composite layup from the stiffness matrices is necessary. This would enable a direct coupling between stiffness adjustments, wing mass and aircraft performance.

Finally, while the base configuration outperforms the final design on peak aerodynamic performance alone, this is not parlayed into superior race performance. A longstanding paradigm in the compartmental design of sailplanes has been to optimize peak aerodynamic efficiency assuming a direct correlation to increased crosscountry performance. While such a correlation exists for rigid aircraft, the presented example illustrates that this is not a general axiom and offers a compelling argument for integrating design disciplines when possible and reasonable.

\section{References}

${ }^{1}$ Munk, M. M., "Propeller Containing Diagonally Disposed Fibrous Material," US Patent 2,484,308,1111, Oct. 1949.

${ }^{2}$ Shirk, M. H., Hertz, T. J., and Weisshaar, T. A., "Aeroelastic Tailoring Theory, Practice, and Promise," Journal of Aircraft, Vol. 23, No. 1, 1987, pp. 6-18.

${ }^{3}$ Herold, W. D., "Concordia, A New Supersailplane: A Transatlantic Pact to Create the Ultimate Soaring Machine," Aerokurier, 2005.

${ }^{4}$ Sobieszanski-Sobieski, J. and Haftka, R. T., Computer Aided Optimal Design: Structural and Mechanical Systems, chap. Interdisciplinary and Multilevel Optimum Design, Springer Verlag, Berlin, 1987.

${ }^{5}$ Thomas, F., Fundamentals of Sailplane Design, College Park Press, College Park, MD, 1999.

${ }^{6}$ Carmichael, B. H., "What Price Performance," Soaring, Vol. May / June, 1954. 
${ }^{7}$ Horstmann, K. H., "Neue Modellaufwindverteilungen und ihr Einfluss auf die Auslegung von Segelflugzeugen," $X V$ OSTIV Congress. Vol. XIV, OSTIV, Rayskala, Finland, 1976.

${ }^{8}$ Quast, A., "Mittlere Reisegeschwindigkeit vermessener Segelflugzeuge unter gleichzeitiger Beruecksichtigung von vier Modellaufwindverteilungen," Aerokurier, 1978, pp. 137-140

${ }^{9}$ Ashby, D., "PMARC Panel Method Ames Research Center," 1994

${ }^{10}$ Drela, M., "XFOIL: An analysis and design system for low Reynolds number airfoils," Low Reynolds Number Aerodynamics, Springer, 1989.

${ }^{11}$ Palacios, R. and Cesnik, C. E. S., "A Geometrically-Nonlinear Theory of Composite Beams with Deformable Cross Sections," AIAA Journal, Vol. 46, No. 2, February 2008.

${ }^{12}$ Palacios, R. and Cesnik, C. E. S., "Cross-Sectional Analysis of Non-Homogeneous Anisotropic Active Slender Structures," AIAA Journal, Vol. 43, No. 12, November 2005, pp. 2624-2638.

${ }^{13}$ Schuerman, H., Kontruieren mit Faser-Kunststoff-Verbund Werkstoffen, Springer, Berlin, 2005.

${ }^{14}$ Puck, A., "Zur Beanspruchung und Verformung von GFK-Mehrschichtenverbund-Bauelementen. Teil 1. Grundlagen der Spannung- und Verformungsanalyse," Kunststoffe, Vol. 57, No. 4, 1967, pp. 284-293.

${ }^{15}$ Foerstner, R. and Knappe, W., "Experimentell und theoretische Untersuchungen zur Rissbildungsgrenze an zweischichtigen Wickelrohren aus Glasfaser/Kunststoff unter Innendruck," Kunststoffe, Vol. 61, No. 8, 1971, pp. 583-588.

${ }^{16}$ Smith, M., Patil, M., and Hodges, D., "CFD-Based Analysis of Nonlinear Aeroelastic Behavior of High-Aspect Ratio Wings," 41st AIAA/ASME/ASCE/AHS/ASC Structures, Structural Dynamics and Materials Conference, AIAA, Seattle, WA, 2001.

${ }^{17}$ Hallissy, B. P. and Cesnik, C. E., "High-fidelity Aeroelastic Analysis of Very Flexible Aircraft," 52nd AIAA/ASME/ASCE/AHS/ASC Structures, Structural Dynamics and Materials Conference, AIAA, Denver, CO, 2011.

${ }^{18}$ Cesnik, C. E. S. and Brown, E. L., "Modelling of high Aspect ratio Active Flexible Wings for Roll Control," Proceedings of the 43rd Structures, Structural Dynamics, and Material Conference, AIAA, Denver, Colorado, April 2005.

${ }^{19}$ Shearer, C. M. and Cesnik, C. E. S., "Nonlinear Flight Dynamics of Very Flexible Aircraft," Journal of Aircraft, Vol. 44, No. 5, 2007, pp. 1528-1545.

${ }^{20} \mathrm{Su}, \mathrm{W}$. and Cesnik, C. E. S., "Nonlinear Aeroelasticitiy of a Very Flexible Blended-Wing-Body Aircraft," Journal of Aircraft, Vol. 47, No. 5, 2010, pp. 1539-1553. 